\title{
Key mechanisms for tritium transfer in the terrestrial environment
}

\author{
PH. GUETAT ${ }^{1}$
}

(Manuscript received 8 October 2012, accepted 18 January 2013)

ABSTRACT During an accidental release of tritium, mechanisms of hydrogen transfer from air to man are very numerous, dependent on multiple climate, physiological and biological parameters, and the kinetic is highly variable from one environmental compartment to another. To evaluate the impact of an acute tritium release requires either an overall assessment of the state of the environment during the release and the following hours from a number of restricted data, or the establishment of a significant data bank, a complex model and a system of data acquisition in real time whose potential for daily purposes is very hypothetical. To facilitate the first approach, this paper discusses the key elements of the mechanisms to guide the choice of parameters for a rapid assessment of the situation, and to clarify the types of measurements to carry out and their interpretation.

Keywords: tritium / accident / environment / modeling / dose assessment

\section{Introduction}

The purpose of this paper is not to review the large volume of literature that describes the processes of transport between the different compartments of the environment. Many authors have presented studies and reviews on exchanges between two compartments (Guenot and Belot, 1984; Garland and Ameen, 1979; Boyer et al., 2009; Melintescu, 2011; Patryl et al., 2011). Many papers present intercomparisons of model predictions (Barry et al., 1999), with experimental work in terms of concentration (see the IAEA programmes: BIOMOVS, BIOMASS (IAEA, 2003), EMRAS I (IAEA, 2012) \& II). In the framework of the EMRAS programme, an integrated approach has been developed (Galeriu et al., 2008), and the present work deals with the key mechanisms and concepts for understanding tritium transfers from air to man, considering all pathways.

\section{Atmospheric transfer}

Atmospheric transport and dispersion is similar to that of other radionuclides, except that HTO is re-emitted from vegetables and soil to air. Re-emission may

\footnotetext{
1 CEA, Cabinet du HC, CEA siège, 91191 Gif-sur-Yvette, France.
} 
PH. GUETAT

represent some ten percent of the deposition and can be neglected in a first approach.

Atmospheric dispersion occurs during this re-emission, lasting many hours, and therefore this secondary exposure pathway is even smaller.

In the situation of accidental release, tritium can be released as a gas (HT) or as tritiated water vapour (HTO).

\section{Tritiated gas (HT)}

It must be noted that HT is not incorporated by plants and has a low dry deposition velocity; furthermore, it is not washed away by rain and has a low dose per unit intake by inhalation. Thus, the only pathway of interest (Galleriu et al., 2008) is the chemical transformation by microorganisms of the small deposit on the soil into mainly tritiated water, and the following use of the water by plants.

In practice, it is necessary to have about "one kilogram" (360 PBq) release of tritium HT to reach a significant impact (some mSv), delivered in some weeks. As this quantity is difficult to reach in any existing factory, the case of HT does not need to be developed. Nevertheless, in a real accident, it is important to know the fraction of HT in the release, as its contribution to impact is negligible compared with tritiated water.

In cases of pure HT release, exposure is of the order of a few percent (1 to 5\%) of exposure of a pure HTO release. It is mainly due to ingestion by the soil-plant pathway, as tritium must first be transformed into tritiated water.

\section{Tritiated water (HTO)}

Pathways for tritiated water are more complex and operate on different scales of time.

It is well known that in the case of a HTO release in the atmosphere, the main pathway of exposure is consumption of food with a contribution of tritiated organic molecules elaborated by photosynthesis, OBT (Organically Bound Tritium) (Diabaté and Honig, 1988).

Nevertheless, models emphasise the definition of instantaneous concentration in the different compartments, which is useful to interpret the measurements but often misses the second objective of the purpose, which is to propose efficient countermeasures. This is why it is interesting to analyse in detail the different mechanisms, their time of occurrence and contribution to the total dose. 
During the accident, many mechanisms of transfer operate depending on a lot of interconnected parameters:

- the first one is the direct transfer from air to leaves by exchange between air vapour and free water of the leaves through the stomata and also through the cuticle. It depends on the Leaf Area Index $\left(\mathrm{m}^{2}\right.$ of leaves per $\mathrm{m}^{2}$ of soil) and on the stomatal resistance, which characterises the opening of the stomata;

- the second pathway is the transfer from air to soil, which occurs by diffusion of air vapour through the surface. It can be modelled with a deposition velocity which depends mainly on the soil humidity.

To quantify these pathways, it is interesting to give some idea of the different contents. The absolute humidity of air is of the order of 5-25 g.m $\mathrm{m}^{-3}$. The quantity of water in $1 \mathrm{~m}^{2}$ of vegetables covering the soil is between 500 and $5000 \mathrm{~g} . \mathrm{m}^{-2}$; and the quantity of water released by transpiration is between 50 and $250 \mathrm{~g} \cdot \mathrm{h}^{-1} \cdot \mathrm{m}^{-2}$. Exchanges by diffusion, both ways, may reach the same levels of flux (cf. Eq. (1)). So, in any case, at least a few hours are required to reach equilibrium between plant free water and air vapour. This also means that there is a general flux from the plant to air and simultaneously a diffusion mechanism between air and the plant. Generally, equilibrium would not be reached in the case of an accident.

As a part of the free water of the plant comes from the soil, at equilibrium the ratio between HTO in plant water and HTO in air vapour is not $100 \%$, but about $40 \%$ (Boyer et al., 2009). The level of this ratio also allows one to suppose that the turnover of the free water of the plant is rapid and of the order of a day.

\section{HTO transfer from air to plant}

Stomata are cellular structures which constitute doors through which the different gases of photosynthesis $\left(\mathrm{CO}_{2}, \mathrm{O}_{2}\right.$ and water vapour) exchange between air and the internal medium of the plant. The cuticle is a more or less impervious layer which covers the epithelium.

Stomata control the flux of transpiration. They are open when there is light and sufficient water coming from soil and can be moderated by some internal regulation (abscissic acid for water stress). Photosynthesis and transpiration will occur when fluxes of $\mathrm{CO}_{2}$ and water are possible.

This transfer depends on many environmental factors such as light, temperature, the relative humidity of the air and soil, and internal factors such as number of stomata, location, sugar concentration, age of the plant, etc. In practice, these data will never be available at the moment of the accident. 
PH. GUETAT

\subsection{Kinetic considerations}

In leaves, charge and discharge of HTO from air are fast phenomena. The concentration increases and decreases with a biological period of the order of an hour during the day. Tritium delabelling of plant tissue after exposure from the atmosphere is much slower in darkness than in the light, loss of HTO primarily depending on transpiration. During the night, the period can last many hours.

Therefore, the exact time of the release is important as most of the decrease phase will occur the following morning, in day conditions.

The activity of leaves increases from zero at the beginning to the maximum at the end of the release and comes back to the low level of soil water activity some hours later.

The dose contribution from the pathway "air - plant free water - man" occurs during the first day for vegetables harvested that day (fresh garden vegetables).

\subsection{Exchange velocity}

From the mathematical point of view, this mechanism is modelled using the parameter "exchange velocity", $V_{c}$, in $\left(\mathrm{m} . \mathrm{s}^{-1}\right)$. It represents the flux of air that enters the leaves (Bq per $\mathrm{m}^{2}$ of soil and per second for $1 \mathrm{~Bq}$ per $\mathrm{m}^{3}$ of air). If we suppose that the exchange velocity between free water of the plant and air vapour remains the same in charge and discharge phases, then the instantaneous concentration increases with time during the release, following a function: $C(t)=C_{\infty}\left(1-e^{-k V_{c} t}\right)$ and decreases after the release following a function $C(t)=C_{\max } e^{-k V_{c} t}$.

The time-integrated concentration of the plant water is far less sensitive than the instantaneous concentration to this exchange rate. Photosynthetic production is bound to this time-integrated concentration and also ingestion by man of tritiated free water of vegetables, but in practice, people do not harvest vegetables continuously, and especially during the night.

Water absorption by the leaves is fast during the day and the velocity is slower during the night. Vapour exchanges occur mainly by stomata of the leaves, for which the mechanism is controlled by internal pressure of bystander cells. Nevertheless, the cuticle is not absolutely watertight, especially for young and old leaves. 
Depending on this pressure, stomata will be more or less open.

- External factors which influence the state of stomata are: the relative humidity of air $(H R)$ and light.

- A moist air $(H R=80 \%)$ promotes the opening of stomata while a drier air $(H R=50 \%)$ closes them.

- Light also plays a direct role in the opening of stomata. It causes a large increase in the osmotic pressure of guard cells (pressure rises from 12 to 18 bars); meanwhile, bystander cell pressure is about 15 bars. From current knowledge, in the stomata guard cells there is accumulation of potassium with inverse transport of protons. This "proton pump" seems to be stimulated by the light, especially in blue radiation.

- As an internal factor, abscissic acid plays a key role. In the case of water stress, its content increases considerably, which causes a quick closure of stomatal orifices. Abscissic acid acts as a hormone of distress and allows a vigorous response of plants.

Following (Belot et al., 1996), the exchange velocity is calculated as follows:

$$
V_{c}=\frac{L A I}{r}
$$

with

$V_{C}$ : water exchange velocity between air and leaves $\left(\mathrm{m} \cdot \mathrm{s}^{-1}\right)$;

LAI: leaf area index at the moment of the release (dimensionless);

$R$ : stomatal resistance of the leaf surface $\left(\mathrm{s} . \mathrm{m}^{-1}\right)$.

The stomatal resistance of the leaf surface, $r$, has a value of $300 \mathrm{~s} . \mathrm{m}^{-1}$ as an average during the day when stomata are completely open and $3000 \mathrm{s.m} \mathrm{m}^{-1}$ during the night when they are closed. Knowing the leaf area index of the different vegetable categories, one can estimate the exchange velocity of water vapour between air and leaves.

The concentration of free water of the leaves during the release is given by:

$$
\frac{d A_{l}}{d t}=\frac{V_{c} C_{w}^{s a t}}{m}\left(H_{r} A_{v a p}-A_{l}\right)
$$

with

$A_{l}$ : activity of leaf free water (Bq. $\mathrm{m}^{-3}$ );

$A_{\text {vap }}$ : activity of water vapour in air (Bq. ${ }^{-3}$ );

$V_{c}$ : water exchange velocity between air and leaves $\left(\mathrm{m} \cdot \mathrm{s}^{-1}\right)$;

$m$ : quantity of water in leaves per $\mathrm{m}^{2}$ of soil $\left(\mathrm{kg} \cdot \mathrm{m}^{-2}\right)$; 
$H r$ : relative humidity of air (no dim);

$C_{w}^{\text {sat }}$ : quantity of water in air at saturation $\left(\mathrm{kg} \cdot \mathrm{m}^{-3}\right)$.

$C_{w}$ (depending on temperature) and $m$ (not very different from yield) can be easily evaluated. $V_{c}$ is the most variable parameter. The half-life of charge and discharge is then given by:

$$
T_{1 / 2}=\frac{m \ln (2)}{V_{c} C_{w}^{s a t} 3600} \quad \text { (in hours). }
$$

$m$ and $V_{c}$ both depend on the leaf area index, so LAI does not appear to be an influent parameter. The half time is proportional to stomatal resistance, and decreases when the temperature of air increases.

Moreover, if the charge and discharge are rapid and in constant conditions, then the time-integrated activity of the free water is independent of the water incorporation rate and equal to the time-integrated activity of air vapour at saturation, but the duration of discharge can be much longer.

In practice, conditions do not remain constant for many hours. A physiological approach is needed to integrate stomatal resistance and leaf area index. It would be the best approach, if it is possible, to evaluate stomatal resistance from available data at the moment of the accident.

\subsection{Practical conclusions}

From the point of view of countermeasures, if there is no consumption of leaves or fruits of vegetables for 2 or 3 days, then this pathway will be avoided.

The main incidence of this free water contamination is that the tritiated organic matter built up during the release and in the following hours or days will be more or less proportional to the integrated activity of the free water of the leaves. The integrated activity of air vapour at saturation can be used, in a first approach, as a maximum of the free water integrated activity.

\section{HTO transfers from air to soil, and soil to air}

The second pathway is the transfer from air to soil, which occurs by diffusion of air vapour through the surface. It can be modelled with a deposition velocity which depends mainly on the soil humidity.

To give some quantitative idea of this mechanism, an assessment of the vapour exchange between air and soil in a temperate climate has been carried out in the environment of Dijon, France (Guetat et al., 2011). In terms of mass and activity 
balances, the equivalent of $300{\mathrm{~L} . \mathrm{y}^{-1}}$ of air vapour is incorporated in the soil,

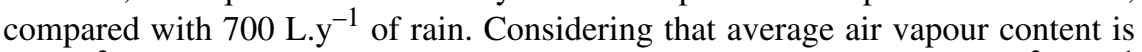
$8 \mathrm{~g} . \mathrm{m}^{-3}$, this gives an average deposition velocity of air of $1.2 \times 10^{-3} \mathrm{~m} \cdot \mathrm{s}^{-1}$ (generally supposed to be between $10^{-3}$ and $10^{-2} \mathrm{~m} \cdot \mathrm{s}^{-1}$ (Belot et al., 1979; Feinhals and Bunnennberg, 1988; Belot et al., 1996)). The average deposition of vapour in one hour is 0.03 to $0.3 \mathrm{~kg} \cdot \mathrm{h}^{-1} \cdot \mathrm{m}^{-2}$.

It is often indicated that about half of the maximal deposition is released to air after the end of the accident. This value is generally used to assess re-emission to calculate a second pathway by inhalation to be exhaustive.

\section{HTO transfer from soil to plant}

At a given moment, the relative humidity of soil is between 10 and $30 \%$, corresponding to 50 and $150 \mathrm{~kg} \cdot \mathrm{m}^{-2}$ for the rooting zone (it can be more for deeper soils).This means that soil water concentration will be, for a short release of $1 \mathrm{~h}$, less than $0.1-1 \%$ of the air vapour concentration. This is small compared with airleaf transfer, which is a few percent at the same time in daytime. Nevertheless, the half time in the soil will be of some weeks instead of some hours for free water in leaves; therefore, the integration time is significant and doses from the soil pathway are not negligible. Considering the fast turnover of free water in the plant, equilibrium between plant and soil will be reached in 2 or 3 days. Therefore, the plant free water concentration will decrease with the same half time as the soil concentration.

From the point of view of countermeasures, the soil-plant pathway needs to be taken into account and assessed during the first week and will need to be confirmed by measurements.

From spring to autumn water evapotranspiration in a temperate climate is of the order of some litres per square metre and per day, compared with the 50-150 L contained in the soil. The decrease in activity in a temperate climate will therefore have a half-life of between 10 and 100 days. The longest period corresponds to the largest soil water content and consequently, to the lowest concentration. Thus, the dose which is bound to integrated activity will not be very different from one case to another.

To assess the decrease in soil water activity, it can be considered that evapotranspiration is the main mechanism which reduces the soil activity. The concept of potential evapotranspiration is used and corresponds to the water loss from a field crop (such as grass) which covers the soil completely and has an optimum supply of water from the soil. 
Homogenisation in soil depth occurs because of hydraulic potential equilibrium related to root distribution and following rain. Therefore, the daily rate of emission may be considered as the ratio of real evapotranspiration to the total quantity of water in the root zone.

$$
\frac{d A_{\text {soil }}}{d t}=- \text { ETR } C_{\text {soil }} \quad \text { and } \quad A_{\text {soil }}=\text { Depth } \theta_{t} D_{a} C_{\text {soil }}
$$

ETR: real evapotranspiration $\left(\mathrm{L} . \mathrm{m}^{-2}\right)$;

$A_{\text {soil }}$ : soil activity $\left(\right.$ Bq. $\left.\mathrm{m}^{-2}\right)$;

$C_{\text {soil }}$ : soil water concentration (Bq. $\left.\mathrm{L}^{-1}\right)$;

$\theta_{t}$ : soil humidity at time $t$ of deposition, unitless $\left(\mathrm{kg}^{\mathrm{kg}} \mathrm{kg}^{-1}\right)$;

Depth: rooting depth (m);

$D_{a}$ : apparent density of soil $\left(\mathrm{kg} \cdot \mathrm{m}^{-3}\right)$.

The critical soil moisture content is defined as the quantity of stored soil moisture below which the plant starts to close its stomata.

Real evapotranspiration is equivalent to potential evapotranspiration when the humidity of soil is above a critical humidity, given by the relation (Van Diepen, 2003):

$\theta_{w s}=(1-p)\left(\theta_{f c}-\theta_{w p}\right)+\theta_{w p}$, which can also be expressed as:

with

$$
p=\frac{\left(\theta_{f c}-\theta_{w s}\right)}{\left(\theta_{f c}-\theta_{w p}\right)}
$$

$\theta_{f c}$ : humidity at field capacity / unitless / soil moisture suction $=0.1 \mathrm{bar}$;

$\theta_{w p}$ : humidity at wilting point / unitless / soil moisture suction $=16$ bars;

$\theta_{w s}$ : humidity at critical point / unitless / closure of stomata, depending on plants and ETP;

$p$ : fraction of easily available soil water / unitless.

$p$ values are indicated in Table I for ETP. We can see that $p$ decreases when potential evapotranspiration increases.

For humidity above $\theta_{w s}$, real evapotranspiration is equivalent to ETP (if the plant covers the surface). Below $\theta_{w s}$, a reduction factor has to be applied and is given by the following equations:

$$
\frac{E T R}{E T P}=R_{w s}=\inf \left(1, \frac{\theta_{t}-\theta_{w p}}{\left(\theta_{w s}-\theta_{w p}\right)}\right)=\inf \left(1, \frac{\theta_{t}-\theta_{w p}}{(1-p)\left(\theta_{f c}-\theta_{w p}\right)}\right)
$$

ETP: potential evapotranspiration $\left(\mathrm{L} \cdot \mathrm{m}^{-2}\right)$. 
TABLE I

Fraction of easily available soil water - soil depletion factor.

\begin{tabular}{|c|c|c|c|c|c|c|c|c|c|c|}
\hline \multirow{2}{*}{ Crop group } & \multicolumn{10}{|c|}{$\operatorname{ETP}\left(\mathrm{mm} \mathrm{d}^{-1}\right)$} \\
\hline & 1 & 2 & 3 & 4 & 5 & 6 & 7 & 8 & 9 & 10 \\
\hline $\begin{array}{l}\text { leaf veg, strawberry, } \\
\text { cabbage, onion }\end{array}$ & 0.53 & 0.45 & 0.38 & 0.30 & 0.25 & 0.23 & 0.20 & 0.18 & 0.16 & 0.15 \\
\hline $\begin{array}{l}\text { clover, carrot, early, } \\
\text { banana, pepper }\end{array}$ & 0.80 & 0.60 & 0.50 & 0.43 & 0.35 & 0.30 & 0.28 & 0.25 & 0.23 & 0.20 \\
\hline $\begin{array}{l}\text { grape, pea, potato, } \\
\text { sunflower, tomato, } \\
\text { watermelon, grass }\end{array}$ & 0.90 & 0.75 & 0.65 & 0.55 & 0.45 & 0.40 & 0.38 & 0.33 & 0.30 & 0.25 \\
\hline $\begin{array}{l}\text { citrus, groundnut, } \\
\text { pineapple, alfalfa, } \\
\text { cotton, cassava, } \\
\text { sweet potato, grains }\end{array}$ & 0.95 & 0.85 & 0.75 & 0.65 & 0.55 & 0.50 & 0.48 & 0.43 & 0.38 & 0.35 \\
\hline $\begin{array}{l}\text { olive, safflower, } \\
\text { sorghum, soya bean, } \\
\text { sugarcane }\end{array}$ & 1.00 & 0.92 & 0.85 & 0.75 & 0.65 & 0.60 & 0.55 & 0.50 & 0.48 & 0.45 \\
\hline
\end{tabular}

For humidity at field capacity and humidity at wilting point, it is necessary to contact local agricultural organisations. As an order of magnitude, field capacity is between 10 (sand) and 40\% (peat) and wilting point between a few percent and $10 \%$, and more for peat.

\section{HTO from air to rain and soil}

It is well known that the concentration of the rain is lower than the air moisture at soil level at some distance (a few hundred metres) from the stack (within the range 10-100\%). Of course, near the stack, rainwater which falls through the plume can have a much higher concentration than air at soil level, depending on the height of the stack.

Quite a lot of equations exist to define washout, rain concentration and deposition on the soil.

The washout rate equation according to rainfall intensity was proposed by several authors as reported by (Melintescu, 2011; Patryl et al., 2011).

$$
\lambda=a(\delta)^{b}
$$

where

$a$ and $b$ are empirical coefficients, we may propose $10^{-5}$ and 0.73 ;

$\delta$ the precipitation intensity $\left(\mathrm{L} . \mathrm{h}^{-1}\right)$;

$\lambda$ the washout rate $\left(\mathrm{s}^{-1}\right)$. 
Deposition is supposed to be proportional to the air integrated concentration in the column washed by the rain. Therefore:

$$
F_{h t o}=\lambda \oiint C(z, t) d z d t
$$

where $\lambda$ is the washout rate $\left(\mathrm{s}^{-1}\right), F_{h t o}$ is the HTO deposition rate $\left(\mathrm{Bq} \cdot \mathrm{m}^{-2} \cdot \mathrm{s}^{-1}\right), C$ is the HTO concentration in air $\left(\mathrm{Bq} \cdot \mathrm{m}^{-3}\right)$, and $z$ is the height above the ground $(\mathrm{m})$.

In practice, HTO concentration in rain does not depend much on the rain intensity and seems to slightly decrease when intensity increases $(b<1)$. So, deposition is more or less proportional to the total quantity of rain $\left(\mathrm{L} \cdot \mathrm{m}^{-2}\right)$. Generally, the quantity of rain in a temperate climate is of the order of some mm. This is small compared with the total quantity of water in the soil. A dilution factor of 10 to 100 interacts in the transfer process from the soil to plant. Finally, HTO in soil water will be about 2 orders of magnitude lower than the HTO in air moisture.

Leaf activities in the case of rain are not well known. One simple approach consists of considering the time needed for evaporation to eliminate the water remaining on the leaves (a few hours). Therefore, the charge period can be much longer than in dry conditions, but this is counterbalanced by the activity of rain, which is generally lower than that of air vapour (except at the stack foot).

\section{Production of tritiated organic matter}

A part of HTO is incorporated in organic matter during photosynthesis. This tritium is called organically bound tritium (OBT). In practice, it includes two very different types of hydrogen: tritium bound to carbon which has practically no decrease up to harvest (carbon-bound tritium or non-exchangeable NE-OBT) and tritium bound to other elements $(\mathrm{O}, \mathrm{N}, \mathrm{S})$ which is easily exchangeable (E-OBT) with hydrogen of free water in a few hours. Depending on the part of the vegetable eaten, the tritiated organic matter built up from air water may be translocated in totality to the accumulation organ after flowering or just before. The influence of the date of the accident is thus important in terms of dose for vegetables which are stored and eaten over a long period such as wheat or potatoes. At some critical periods of the year (like in June under a European climate) the total dose may be quite markedly reduced by stopping the culture and by replacing it (if possible) with a new one.

Simultaneously, some deposition occurs on the ground and also contributes to the contamination of the plants by the root pathway and incorporation of tritium in organic material. The soil concentration of HTO is much smaller than that in vapour, but the soil HTO has a much smaller turnover and will lead to a continuous 
production of OBT up to harvest. Rain may increase the deposition to the soil quite a lot and is a particular point to take into account.

The organic compounds of a plant are produced by photosynthesis transforming sunlight energy into chemical energy. The general reaction produces a C3 molecule $(\mathrm{H}-\mathrm{C}-\mathrm{OH})_{3}+\mathrm{O}_{2}$ from $\mathrm{CO}_{2}$ and $\mathrm{H}_{2} \mathrm{O}$. We can see that each carbon corresponds to a molecule of $\mathrm{H}_{2} \mathrm{O}$ and may suppose this equivalence as a basic approach. In fact, only one $\mathrm{H}$ (or even less in chains of polymers) is carbon-bound. Total Organic Tritium increases by exchange with free water much more quickly than by photosynthesis, and decreases in the same way (Guetat et al., 2011). Carbon bound tritium is far less significant after an acute contamination, and its measurement needs to eliminate totally the exchangeable tritium, which is a source of technical difficulties. Other overestimation may come from "buried water" in macromolecules included as carbon bound tritium (Kim and Baumgärtner, 1994). As the dose per unit intake conversion factor given by the International Commission on Radiological Protection (ICRP, 1989) supposes 50\% of exchangeable tritium in organic matter, the best method is to remain consistent with this approach.

From continuous normal release, the average incorporation rate can be calculated from the yield of dry matter at harvest divided by the time of growth multiplied by a ratio of 0.53 , which corresponds to the proportion of $\mathrm{H}_{2} \mathrm{O}$ in C3 molecules corrected by a discrimination factor of 0.95. (DeVol and Powell, 2004) report values leading to 0.57 to 0.6 for vegetables, without discrimination.

$$
\tau_{\text {inc }}=0.53 \frac{\tau_{d m}^{v e g} Y}{86400 \Delta t_{\text {growth }}}
$$

with

$\tau_{\text {inc }}:$ incorporation rate of tritium in organic matter $\left(\mathrm{kg}_{\mathrm{water}} \cdot \mathrm{m}_{\mathrm{soil}}{ }^{-2} \cdot \mathrm{s}^{-1}\right)$;

0.53 : water equivalence of dry organic matter $\left(\mathrm{kg}_{\text {water }} \cdot \mathrm{kg}_{\text {dry plant }}{ }^{-1}\right)$;

$\tau_{d m}^{v e g}$ : dry matter content in the vegetable $\left(\mathrm{kg}_{\text {dry plant }} \cdot \mathrm{kg}_{\text {fresh plant }}{ }^{-1}\right)$;

$Y$ : yield at harvest $\left(\mathrm{kg}_{\text {fresh plantl }} \cdot \mathrm{m}_{\text {soil }}{ }^{-2}\right)$;

86400: conversion factor $\left(\mathrm{s} . \mathrm{d}^{-1}\right)$;

$\Delta t_{\text {growth }}$ : growth duration of the vegetable (d).

This type of very simple approach does not make any difference between day and night or between cold, warm and hot weather. It should be at least corrected by the daylight ratio per day, as there is no incorporation by the light reactions during the night (dividing by about 0.6 for summertime), but on the other hand, only one $\mathrm{H}$ is carbon-bound and corresponds to real NE-OBT. 
As the effect of temperature is relatively important for incorporation, it is useful to refine equations to include this parameter. The simplest approach is therefore to consider the general case and to characterise the extreme cases.

As soon as the sun rises, the photosynthetic mechanisms operate. Light is thus never the limiting factor of this process. As it is a chemical process, temperature plays an important part in the speed of the reactions. At the same time, respiration is minimal for temperatures around $20{ }^{\circ} \mathrm{C}$ and increases for low temperature and high temperature. The net photosynthesis becomes zero when the temperature of the leaf reaches about $35^{\circ} \mathrm{C}$. At low temperature, the balance becomes positive above a given temperature depending on the crop considered. Values of 0,5 and $7.5{ }^{\circ} \mathrm{C}$ are often used (depending on the geographical origin of the plant; for example, grass-wheat-maize). A first-order relationship may be considered for temperatures between 10 and $30{ }^{\circ} \mathrm{C}$.

A very useful concept for expressing heat units is "total degree days": that is, the accumulated number of daily average temperature above the crop base temperature.

$$
T D D_{\text {harvest }}=\sum_{i=1}^{n}\left(\theta_{i}-\theta_{0}\right)
$$

with

$\theta_{0}$ : crop base temperature $\left({ }^{\circ} \mathrm{C}\right)$;

$n$ : number of days from emerging to harvest; $T D D_{\text {harvest }}:$ total degree days above $\theta_{0}\left(\mathrm{~d} .{ }^{\circ} \mathrm{C}\right)$.

Considering that air temperature is an available piece of data, and considering that in the general case the incorporation rate is proportional to temperature, then it is possible to consider the previous equation in order to introduce the temperature and total degree days, instead of growth duration

$$
\tau_{\text {inc }}=0.53 \frac{\tau_{d m}^{\text {veg }} Y\left(\theta-\theta_{0}\right)}{24 T D D_{\text {harvest }}}
$$

with

$\tau_{\text {inc }}$ : incorporation rate of tritium in organic matter $\left(\mathrm{kg}_{\mathrm{water}} \cdot \mathrm{m}_{\mathrm{soil}}{ }^{-2} \cdot \mathrm{h}^{-1}\right)$;

0.53: water equivalence of dry organic matter $\left(\mathrm{kg}_{\text {water }} \cdot \mathrm{kg}_{\text {dryplant }}{ }^{-1}\right)$;

$\tau_{d m}^{v e g}:$ dry matter content in the vegetable $\left(\mathrm{kg}_{\text {dry plant }} \cdot \mathrm{kg}_{\text {fresh plant }}{ }^{-1}\right)$;

$Y$ : yield at harvest $\left(\mathrm{kg}_{\text {fresh plant }} \cdot \mathrm{m}_{\text {soil }}{ }^{-2}\right)$;

24: conversion factor(h. $\left.\mathrm{d}^{-1}\right)$;

$\theta$ : average temperature during the accident and following hours $\left({ }^{\circ} \mathrm{C}\right)$. 
It is also possible to be freed from the surface dimensions $\left(\mathrm{m}_{\text {soil }}{ }^{-2}\right)$ by dividing the incorporation rate by the dry matter yield $\left(\mathrm{kg}_{\mathrm{dm}} \cdot \mathrm{m}^{-2}\right)$ to obtain a mass incorporation rate expressed in $\mathrm{kg}$ of water per $\mathrm{kg}$ of dry matter per hour.

This allows calculating the activity integrated inside the whole plant, which is interesting for leaf vegetables, but cannot be used for grains or fruits, because the metabolism of these crops changes during growth and partitioning occurs between the different organs of the plants.

Figure 1 shows a measured mass incorporation rate for soya bean from the IAEA EMRASS I WG2 soya bean scenario (IAEA, 2012) (ratio between combustion water activity at harvest and time-integrated activity of air vapour). It can be seen that the total incorporation rate reaches a maximum at the beginning of August, the best time for photosynthesis/temperature for a well-developed cover. It can be seen that the incorporation rate remains relatively stable for leaves after blooming. On the contrary, most of the incorporation is done by transfer from the leaves to pods and grains. This is typically plant-dependent and requires a database for the physiology of the different plants eaten by the population.

These translocation mechanisms are important as edible parts of the plants are generally accumulation organs such as grains, tubers or fruits. These organs will cumulate organic matter labelled through air-plant and soil-plant pathways in great part. Generally, these edible parts contain more dry organic matter than leaves and will be eaten for quite a long time after harvest.

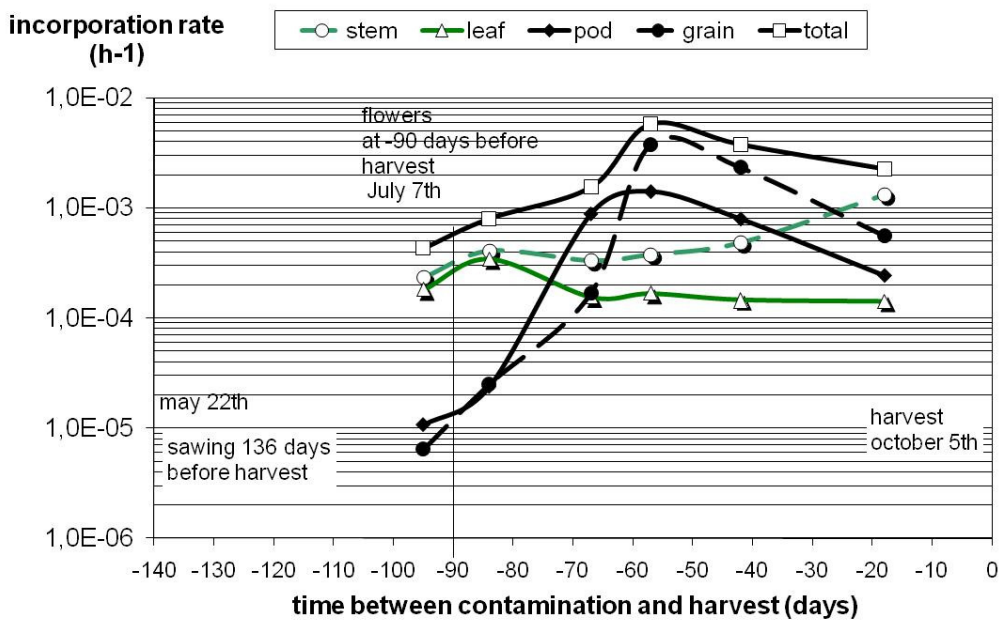

Figure 1 - Measured incorporation rate of tritium in soya bean organic matter. 


\section{Tritiated organic matter produced in the night}

The case of the night is a special case for which relatively large discrepancies in models still exist. Some models do not take into account any incorporation of tritium because stomata are closed and the first photosynthesis reaction of the light phase does not exist. Some other models make no difference between night and day, because some chemical reactions exist during the photosynthesis dark phase, stomata closure is not absolute and some transfer through the cuticle exists, and finally, because of a "pessimistic approach".

Some experimental work exists and shows that some incorporation exists, but the concentration reached seems to be lower than during the day. Many explanations may be given:

- it is clear that many chemical reactions exist during the night, and that some incorporation of hydrogen directly on carbon occurs. Nevertheless, the temperature is lower during the night and this limits the velocity of the chemical synthesis;

- tritiated organic matter activity depends on time-integrated concentration of free water, and as the exchange velocity between air and free water is small in night conditions, the maximum reached at the end of release is small compared with the maximum in day conditions. Integrated activity during the charge phase is also lower. This can also be the case during the discharge phase, especially when the contamination occurs at the end of the night;

- tritiated water remains sufficiently in the plant to be incorporated in the morning;

- finally, exchange of hydrogen and tritium in organic matter also occurs quickly in the night and measurement of exchangeable and non-exchangeable tritium is not so easy.

For all these reasons, it seems to be reasonable to recommend in the case of night contamination the same equation to establish the incorporation rate, but calculated at the night temperature and with the night kinetic of exchange velocity of water between air and plant free water.

\section{Animals}

In the framework of the EMRASS II IAEA programme, quite a complete overview of the dynamic models for tritium transfer to animal products is presented (Galeriu et al., 2001, 2007, 2009; Galeriu and Melintescu, 2011). The purpose here is to integrate all the processes together after an accidental release. 
In the case of accidental release, animals will be tritiated in the very short term, slightly by inhalation and mainly by grass free water ingestion, if they are grazing. The product of interest is thus milk (cow, sheep). The free water and exchangeable organic tritium of the grass, resulting from the air pathway, will be incorporated mainly within the first day and will follow the water cycle in the animal with a turnover of some days (around 2 to 4 days). So, the milk of grazing animals will contain HTO from the air pathway with a maximum reached on the 2nd or 3rd day and a decrease over 2 or 3 weeks. After the first two days, the animal will continue to incorporate simultaneously tritiated organic matter from the air pathway at a constant level of activity per day for the time of the whole pasture (2 to 3 months), and also water and tritiated organic matter from the soil pathway. This last pathway has a decay period of some weeks, so the equilibrium between the soil, grass and animal will be reached and the concentration of the milk water will be the concentration of the intake water (food and drink).

Nowadays, very often, animals no longer graze, and grass is cut and brought to cattle in industrial farming. Animals are therefore protected against an immediate contamination. The choice of grass location is thus an easy way to reduce contamination.

Here again, it is useful to consider separately tritiated water and tritiated organic molecules ingested by the animals. For dosimetric purposes, it is possible to assess the time-integrated activity of milk and meat from the global intake by the animals, using the transfer factors presented for normal conditions (IAEA, 2008).

The proposed model explicitly takes into account transfers from HTO in the diet to HTO and OBT in the product, and from OBT in the diet to HTO and OBT in the product. It is expressed in terms of transfer coefficients; the equilibrium activity concentrations of HTO and OBT in fresh weight animal products are given by:

$$
\begin{aligned}
& C I_{a f w}^{H T O}=F_{H H} I I^{H T O}+F_{O H} I I^{O B T} \\
& C I_{a f w}^{O B T}=F_{H O} I I^{H T O}+F_{O O} I I^{O B T} .
\end{aligned}
$$

Here, $C I$ is the integrated concentration in the product (Bq.d.kg ${ }^{-1}$ ),

$F_{H H}$ is the transfer coefficient from HTO in the diet to HTO in the animal product (d. $\left.\mathrm{kg}^{-1} \cdot \mathrm{FW}\right)$;

$F_{H O}$ is the transfer coefficient from HTO in the diet to OBT in the animal product (d. $\left.\mathrm{kg}^{-1} \cdot \mathrm{FW}\right)$;

$F_{O H}$ is the transfer coefficient from OBT in the diet to HTO in the animal product $\left(\right.$ d. $\left.\mathrm{kg}^{-1} . \mathrm{FW}\right)$; 
$F_{O O}$ is the transfer coefficient from OBT in the diet to OBT in the animal product (d. $\left.\mathrm{kg}^{-1} \cdot \mathrm{FW}\right)$;

II $^{H T O}$ is the animal total intake of $\mathrm{HTO}(\mathrm{Bq})$; and $\mathrm{II}^{\mathrm{OBT}}$ is the total animal intake of $\mathrm{OBT}(\mathrm{Bq})$.

$$
H_{\text {man }}=\left(C I_{a f w}^{H T O} D F_{H T O}+C I_{a f w}^{H T O} D F_{O B T}\right) I_{m a n} .
$$

Here, $I_{\operatorname{man}}$ is the daily intake of milk or meat by man, and $H_{\text {man }}$ is the corresponding effective dose.

In practice, as was seen in (IAEA, 2012), in the framework of the EMRAS I programme, in an intercomparison exercise, milk and meat are not the major pathways in the case of an accident (about 10\% contribution) and do not need countermeasures for a release of $10 \mathrm{~g}$ of HTO (3.6 PBq) (IAEA, 2012). One reason is probably that quite a large quantity of water is incorporated by drinking uncontaminated water; another is that the biological turnovers are relatively speedy.

\section{Conclusions and discussion for practical consequences in the case of accidental release}

Figure 2 illustrates the evolution of tritium activity in vegetables per square metre versus time, considering the two pathways (air and soil) and the two chemical forms (tritiated water and tritiated organic molecules). We can see that the different mechanisms occur at different times; HTO built up a large part of the dose in the short term, and OBT in the longer term (Guetat and Patryl, 2004). This effect is reinforced by the consumption of some particular foods, potatoes and grains, which are eaten after harvest for many months.

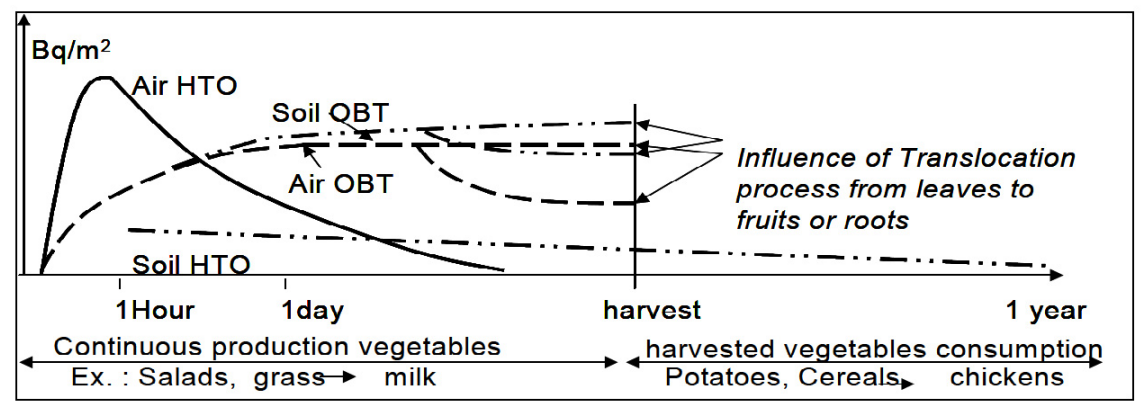

Figure 2 - Evolution of activities with time by the different pathways. 
The results of the EMRAS I WG2 intercomparison exercise for a release of $10 \mathrm{~g}$ of tritiated water at $1 \mathrm{~km}$ (Guetat et al., 2008; IAEA, 2012) show that all the different pathways (air, soil, free water and OBT) contribute to the total dose. It is especially interesting to note that the soil pathway can be as important as the air pathway. The main differences between models and/or modellers concern OBT. The EMRAS II WG7 concludes that tritium is incorporated in organic matter even during the night. Translocation of tritiated organic molecules from leaves to edible parts must also be considered, in order not to overestimate exposure.

In the case of a tritiated water accidental release, the question of the types of measurements has to be addressed. There is in fact no real need to measure nonexchangeable organic tritium, because as seen previously, the instantaneous organic tritium level is much lower than the free water tritium level; the integrated exposure is of the same order of magnitude and this measurement requires a lot of time. On the other hand, when high release is possible (>10 PBq), it is useful to have at least one measurement of air vapour time-integrated activity associated with a free-water measurement of vegetables, and rain concentration and amount in the case of rain. It is also useful to follow the decrease in tritium concentration with time for some days to evaluate the integrated activity of the free water, and in that way, have a better idea of the non-exchangeable organically bound tritium.

Knowing that tritium activity of vegetables decreases after an accident by about a factor of 10 between $1 \mathrm{~h}$ and $48 \mathrm{~h}$, it is interesting to keep in mind that a reference level of $10^{6} \mathrm{~Bq} / \mathrm{kg}$ fresh weight after 2 days could be considered (Guetat and Patryl, 2008), for food restriction in the post-accidental phase, to limit exposure at a maximum of $10 \mathrm{mSv}$ for an autarchic consumption, or $1 \mathrm{mSv}$ for normal consumption.

Protection of the population therefore seems to be quite easy and concerns food consumption suspension or perhaps banning food, and the post-accidental situation should not last more than one season.

\section{REFERENCES}

Barry P.J., Watkins B.M., Belot Y., Davis P.A., Edlund O., Galeriu D., Raskob W., Russell S., Togawa O. (1999) Intercomparison of model predictions of tritium concentrations in soil and foods following acute airborne HTO exposure, J. Environm. Radioact. 42, 191-207.

Belot Y., Gauthier D., Camus H., Caput Cl. (1979) Prediction of the flux of tritiated water from air to plant leaves, Health Phys. 37, 575-583.

Belot Y., Roy M., Metivier H. et al. (1996) Le tritium de l'environnement à l'homme IPSN. Éditions de Physique, Paris.

Boyer C., Vichot L., Fromm M., Losset Y., Tatin-Frouxa F., Guétat Ph., Badot P.M. (2009) Tritium in plants: A review of current knowledge, Environm. Experim. Botany 67, 34-51.

DeVol T.A., Powell B.A. (2004) Thorical organically bound tritium dose estimates, Health Phys. 86, 183-186. 
PH. GUETAT

Diabaté S., Honig D. (1988) Conversion of molecular tritium to HTO and OBT in plants and soils, Fusion Technol. 14, 1235-1239.

Feinhals J., Bunnennberg C. (1988) Laboratory investigations of HTO deposition to soils, Fusion Technol. 14, 1253-1257.

Galeriu D., Crout N.M.J., Melintescu A., Beresford N.A., Peterson S.-R., Van Hess M. (2001) Metabolic derivation of tritium transfer factors in animal products, Rad. Environm. Biophys. 40, 325-334.

Galeriu D., Melintescu A., Beresford N.A., Crout N.M.J., Peterson, R., Takeda H. (2007) Modelling ${ }^{3} \mathrm{H}$ and ${ }^{14} \mathrm{C}$ transfer to farm animals and their products under steady state conditions, $J$. Environm. Radioact. 98 (1-2), 205-217.

Galeriu D., Davis Ph., Raskob W., Mellintescu A. (2008) Tritium radioecology and dosimetry - Today and tomorrow, Fusion Sci. Technol. 54 (1), 237-243.

Galeriu D., Melintescu A., Beresford N.A., Takeda H., Crout N.M.J. (2009) The dynamic transfer of ${ }^{3} \mathrm{H}$ and ${ }^{14} \mathrm{C}$ in mammals: a proposed generic model, Radiat. Environ. Biophys. 48 (1), 29-45.

Galeriu D., Melintescu A. (2011) A model approach for tritium dynamics in wild mammals, Radioprotection 46 (6), S445-S451.

Garland J.A., Ameen M. (1979) Incorporation of tritium in grain plants, Health Phys. 36, 35-38.

Guenot J., Belot Y. (1984) Assimilation of ${ }^{3} \mathrm{H}$ in photosynthesizing leaves exposed to HTO, Health Phys. 47, 849-855.

Guetat Ph., Patryl L. (2004) Analysis of the consequences of an acute atmospheric release of tritium, "Tritium 2004 baden-baden", Fusion Sci. Technol. 48 (1), 441-444.

Guetat Ph., Patryl L. (2008) Environmental and radiological impact of accidental tritium release"Tritium 2007 Rochester", Fusion Sci. Technol. 54 (1), 273-276.

Guetat Ph., Douche C., Hubinois J.C. (2008) Le tritium et l'environnement : sources, mesures et transferts, Radioprotection 43, 547-569.

Guetat Ph., Boyer C., Tognelli A. Duda J.M. (2011) 50 years Environmental Tritium transfer review in the vicinity of a French Research centre, Tritium 2010, Fusion Sci. Technol. 60 (4), 1238-1243.

IAEA (2003) Modelling the environmental transport of tritium in the vicinity of a long term atmospheric and sub-surface sources, http://www-pub.iaea.org/MTCD/publications/ PDF/Biomass3_web.pdf

IAEA (2008) Davis P.A., Leclerc E., Galeriu D.C., Melintescu A., Kashparov V., Peterson S.-R., Ravi P.M., Siclet F., Tamponet C., Specific activity models and parameter values for tritium, ${ }^{14} \mathrm{C}$ and ${ }^{36} \mathrm{Cl}$ in IAEA-TECDOC-1616, Quantification of Radionuclide Transfer in Terrestrial and Freshwater Environments for Radiological Assessments.

IAEA (2012) Environmental Modelling for radiation Safety (EMRAS), A summary report of the results of the EMRAS Programme (2003-2007), Modelling the Environmental Transfer of tritium and Carbon-14 to biota and Man, IAEA-TECDOC-1678 Companion CD

ICRP publication 56 (1989) Hydrogen, Ann. ICRP 20 (1), 15-19.

Kim M.-A., Baumgärtner F. (1994) Equilibrium and non-equilibrium partition of tritium between organics and tissue water of different biological systems, Appl. Radiat. Isotopes 45, 353-360.

Patryl L., Galeriu D., Armand P., (2011) Sensitivity Analysis of Rain Characteristics on HTO Concentration in Drops, Fusion Sci. Technol. 60 (4), 1228-1231.

Melintescu A. (2011) Processes and parameters in modelling dry and wet deposition of radionuclides, part of Ph.D. thesis, Romania X.

Van Diepen, Driessen P.M., van der Goot E., Goudriaan J., Hijmans R.J., Hooijer A.A., van Keulen H., van Kappel R.R., de Koning G.H.J., van Kraalingen D.W.G., Kropff M.J., van Laar H.H., Rappoldt C., Penning de Vries F.W.T., Spitters C.J.T., Supit I., van der Wal T., Wolf J. (2003) WOFOST: Updated system description of the WOFOST crop growth simulation model as implemented in the Crop Growth Monitoring System applied by the European Commission, I. Supit, E.van der Goot (Eds). 